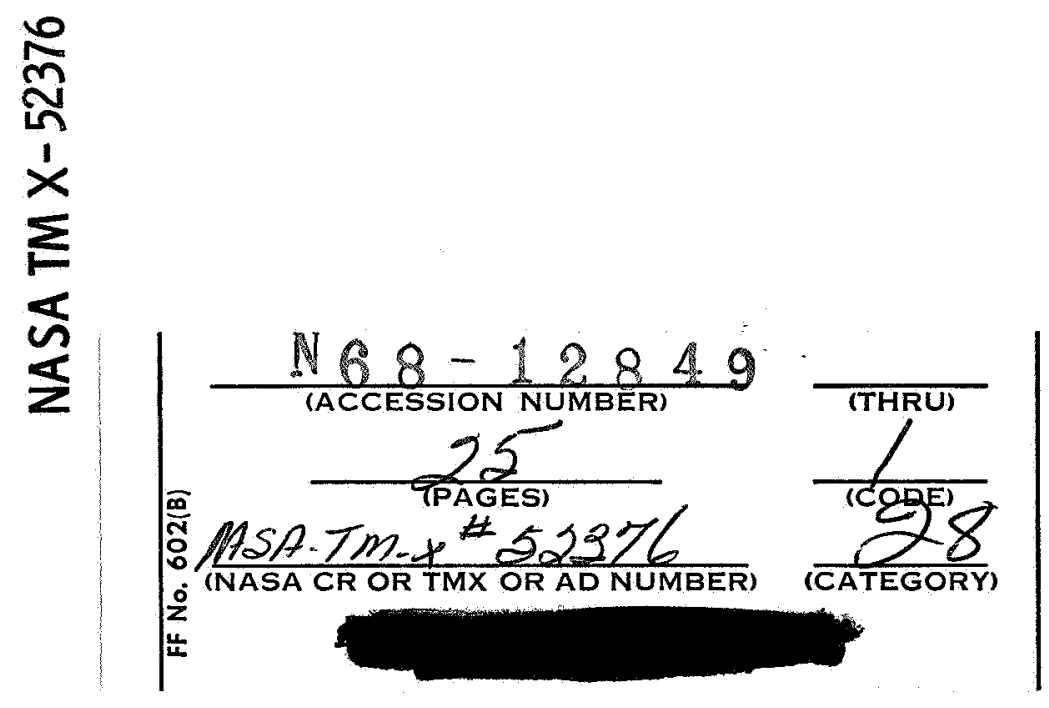

GPO PRICE

$\$$

CFSTI PRICE(S) \$

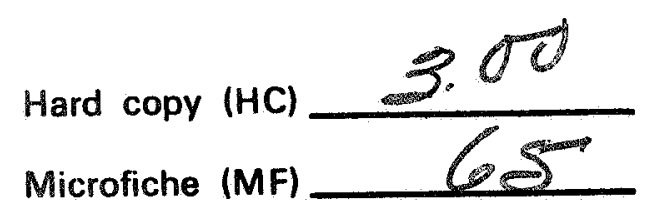

fิ 653 July 65

\title{
PERFORMANCE OF A 15-CENTIMETER' DIAMETER, HOLLOW-CATHODE KAUFMAN THRUSTOR
}

by R. T. Bechtel, G. A. Csiky, and D. C. Byers

Lewis Research Center

Cleveland, Ohio

TECHNICAL PAPER proposed for presentation at Sixth Aerospace Sciences Meeting sponsored by the American Institute of Aeronautics and Astronautics New York, New York, January 22-24, 1968 
PERFORMANCE OF A 15-CENTIMETER DIAMETER, HOLLOW-CATHODE KAUFMAN THRUSTOR

\author{
by R. T. Bechtel, G. A. Csiky, and D. C. Byers \\ Lewi.s Research Center \\ Cleveland, Ohio
}

TECHNICAL PAPER proposed for presentation at

Sixth Aerospace Sciences Meeting

sponsored by the American Institute of Aeronautics and Astronautics

New York, New York, January 22-24, 1968

NATIONAL AERONAUTICS AND SPACE ADMINISTRATION 


\title{
CH DIA \\ PERFORMANCE OF A 15-CENTIMETER DIAMETER, HOLLOW-CATHODE KAUFMAN THRUSTOR
}

\author{
R. T. Bechtel, G. A. Csiky, and D. C. Byers \\ Lewis Research Center \\ National Aeronautics and Space Administration
}

Cleveland, Ohio 44135

\section{Abstract}

A mercury bombardment 15-centimeter diameter, permanent magnet Kaufman thrustor is planned for the SERT II mission. The original thrustor design used a thermionic, oxide magazine cathode, but the advantages of a hollow cathode prompted its substitution. The changes in the thrustor were a redesign of the magnetic field shaping pole pieces and the propellant feed system. Additions to the thrustor were a baffle and a keeper electrode. Baffles of several designs were located on the thrustor axis downstream from the cathode. These baffles were found to significantly effect the propellant utilization efficiency and discharge chamber losses. The keeper electrode aided in starting and maintaining a stable cathode discharge. The effect of the magnitude of the neutral propellant flow through the hollow cathode was also investigated. The final thrustor configuration has been endurance tested for over 2000 hours at discharge losses of $250 \mathrm{ev} / \mathrm{ion}$ and a propellant utilization efficiency of 85 percent. The beam current was 0.25 ampere at a net accelerating voltage of +3000 volts.

\section{Introduction}

A 15-centimeter diameter, electron-bombardment thrustor has been developed for the SERT (Space Electric Rocket Test) II mission: (1), (2) The initial thrustor design utilized a thermionic oxide magazine cathode. This type of cathode has demonstrated lifetimes in excess of 3000 hours, ${ }^{(3)}$ but it can chemically deactivate upon exposure to air after heating and cannot readily be pre-tested in a flight qualified system. Also the required heating powers ranged from 8 to 12 percent of total thrustor power. These disadvantages prompted an experimental program to develop a competitive thrustor using a hollow cathode for the SERT II mission.

A hollow cathode can be retested a number of times even after exposure to air. The heating power required is about 2 percent of the total thrustor power. Cathode lifetimes in excess of 2000 hours have been obtained when the discharge voltage was restricted to the midthirty volt range. Projected lifetimes based on these results exceed 10000 hours.

Disadvantages of a hollow cathode are the addition of a keeper electrode to aid in starting the cathode discharge, and the addition of a baffle to improve discharge chamber efficiency. This type of baffle was initially investigated with a liquid metal cathode in Ref. 4. An additional complication is that some propellant must be introduced through the cathode with the remainder introduced directly into the discharge chamber. Thrustor performance was found to be strongly dependent on the baffle geometry and the fraction of propellant flow through the cathode. Departures from the previously optimized thrustor parameters such as number of magnets, pole piece geometries, and ion extraction system described in Ref. 1, were found unnecessary.

A flight model thrustor based on the results of this development program was tested for more than 2000 hours in a 7.6-meter diameter vacuum facility. Control of the thrustor was achieved by maintaining a constant discharge current and sensing the beam current to regulate the main propellant flow. The cathode propellant flow was regulated manually, although this would not be necessary if a flow splitting device, designed to provide the desired ratio of propellant flows were incorporated in the propellant feed system.

\section{Apparatus and Procedure}

\section{Permanent Magnet Thrustor}

The 15-centimeter diameter Kaufman thrustor used in this program was the SERT II thrustor described in Ref. 1 and shown in Fig. 1. A section of the thrustor is presented in Fig. 2, showing the permanent bar magnets, magnetic screen collar and pole piece, distributor pole piece, cathode, keeper, and baffle.

Fig. 3 shows the cathode-pole piece assembly in greater detail. The relative locations of the cathode keeper, cathode tip, and baffle are shown. The distributor pole piece was 3.8 centimeters in outside diameter and 3.2 centimeters long. The magnetic collar and pole pieces at both ends of the ion chamber were 0.06 centimeter thick, 1020 low-carbon steel.

The magnets used were Alnico $\mathrm{V}$ bar magnets, 0.63centimeters in diameter, having a residual magnetism of 1.1 tesla and coercive force of 500 oersteds. The magnets extended the length of the thrustor and were equally spaced for an eight magnet configuration. The six magnet configuration was obtained by removing two magnets, 180 degrees apart.

\section{Cathode, Keeper, and Baffle}

The cathode tip used was the same design as the plasma-bridge neutralizer ${ }^{(5)}$ and the hollow cathode. $(2)$ It was a 0.32 -centimeter diameter tantalum tube with a 0.1 centimeter thick, 2 percent thoriated tungsten disk, electron beam welded to the end (fig. 4). An orifice was cut in the tungsten disk. The upstream diameter (nearest the insert) was nominally 0.015 centimeters. 
and the downstream diameter nominally 0.030 centimeters. The cathode was heated by coil of tungstenrhenium wire, insulated by a flame sprayed coating of aluminum oxide. Ten or more warps of 0.001 centimeter thick tantalum foil (not shown in fig. 4) were used for heat shielding.

A cathode insert was made of 0.001 centimeter thick tantalum foil coated with a thin layer of a comercially available barium carbonate slurry. After air drying, the foil was rolled and inserted into the cathode tube. This insert dispensed barium oxide to provide a low work function surface to aid in starting the cathode discharge.

The cathode keeper was a loop of 0.15 -centimeter diameter tantalum wire with a nominal inner diameter of 0.63 centimeters. The keeper was mounted nominally 0.15 centimeters downstream of the cathode tip by a single wire through the boron nitride insulator. The circular baffle (fig. 3) was fabricated from 0.02 centimeter thick tantalum and was mounted from two tantalum rods through the boron nitride insulator so that the axial position of the baffle could easily be varied.

\section{Accelerator Grid System}

The accelerator system developed for the SER T II thrustor was used in all tests. The screen grid (upstream electrode) was 71 percent open within a nominal diameter of 13.9 centimeters. The large open area lowered the discharge chamber losses as described in Ref. 1 . The diameter of the screen grid holes was 0.399 centimeters and the diameter of the accelerator holes was 0.326 centimeters. The holes in both grids were drilled in a hexagonal array with a 0.450 centimeter center-tocenter spacing.

\section{Vaporizer and Feed System}

The mercury propellant feed system utilized two porous tungsten vaporizers. (1), (6) The main vaporizer was 0.63 -centimeter diameter and regulated mercury flow through the distributor back plate directly into the discharge chamber (fig. 2). The cathode vaporizer was .0.32-centimeter diameter and regulated the cathode neutral flow.

Both vaporizers were fed from precision bore, 0.1 centimeter diameter, glass tubes. An average neutral flow was determined by measuring the change in the height of mercury in the tube in a given time interval. Flow measurement accuracies of \pm 3.5 equivalent milliamperes were achieved with this system for a time interval of 6 minutes.

\section{Vacuum Facility}

All short term thrustor tests were conducted in a 1.5-meter diameter, 4.5-meter long vacuum tank. The thrustor was mounted in a metal bell jar separated from the tank by a 0.9 -meter diameter gate value. Tank pressure varied from $4 \times 10^{-6}$ to $8 \times 10^{-6}$ torr and bell jar pressure from $7 \times 10^{-6}$ to $2 \times 10^{-5}$ torr during thrustor operation.

Long term endurance tests (2000 hours) were conducted in a 7.6-meter diameter, 18.3-meter long vacuum facility. The thrustor was mounted in a 3-meter diameter bell jar separated from the main vacuum chamber by a gate value. Pressure in both compartments ranged from 1 to $5 \times 10^{-7}$ torr during thrustor operation.

\section{Thrustor Operation}

To start the cathode discharge, the cathode tip was preheated to approximately $1000^{\circ} \mathrm{C}$. The keeper was biased 300 volts positive with respect to the cathode and neutral propellant flow introduced through the cathode. The discharge would normally start at some propellant flow between 10 and 50 equivalent milliamperes, and the keeper-cathode voltage was then lowered to less than 50 volts. The main propellant flow was introduced into the discharge chamber through the distributor. A cathode-anode bias of 60 volts was sufficient to start the main discharge. The keeper-cathode voltage was 9 to 12 volts at 0.3 to 0.5 amperes with the main discharge on. The net accelerating potential and total potential difference were +3000 volts and 5000 volts, respectively, for all tests. An electrical schematic is shown in Fig. 5 .

\section{Results and Discussion}

The variables which were primarily considered in evaluation of the hollow-cathode thrustor were the discharge chamber losses (discharge chamber power divided by ion beam current, $\mathrm{E}_{\mathrm{I}}$, ev/ion), the discharge voltage, and the propellant utilization efficiency (ion beam current divided by equivalent neutral propellant flow, $\eta_{\mathrm{u}}$, percent). The discharge voltage is a major factor in determining cathode lifetime since it determines the energy of ions striking the cathode, and thus the sputtering rate at the cathode surface. The maximum discharge voltage at which satisfactory lifetime has been achieved to date is 36 volts.

Initial testing was aimed at making the hollowcathode thruster competitive with a similar thrustor using a thermionic oxide cathode. Early tests revealed that the value of the cathode propellant flow significantly effected thrustor operation. Therefore, the propellant flows were reproduced as close as possible in all tests where flow was not a variable. The cathode propellant flow was 30 to 40 equivalent milliamperes, except where noted. The effects of propellant flows on thrustor operation are shown later in a performance mapping of a typical thrustor configuration.

\section{Pole Piece Dimensions}

In Fig. 6, discharge chamber losses are plotted as a function of the ion beam current for four different distributor pole piece configurations. The neutral flow was held constant in the range of 330 to 350 equivalent milliamperes. The lowest discharge chamber losses at all ion beam currents were obtained with a pole piece of 3. 8-centimeters diameter and 3.2 centimeters long. This size pole piece provided thrustor operation comparable to a thermionic cathode thrustor and was used for all other tests.

\section{Magnetic Field Strength}

The effect of the magnetic field strength was studied by comparing performance of similar thrustors having both six and eight magnets. Fig. 7 shows that 
the stronger magnetic field gave considerably lower discharge chamber losses and higher discharge voltages. Magnet mounting restrictions and high discharge voltages limited the number of magnets to eight. Other tests with thermionic cathodes indicated no significant improvement in thrustor performance and instabilities in thrustor operation for higher magnetic field strengths.(1)

\section{Cathode Position}

The cathode was initially positioned in the plane of the distributor for ease of mechanical assembly. Tests were conducted to determine the effect of moving the cathode tip forward into the distributor pole piece. Fig. 8 shows a slight degradation in discharge chamber losses and propellant utilization efficiency for the cathode located 2.2 centimeters from the plane of the distributor. All other tests were performed with the cathode located flush with the distributor.

\section{Baffle}

The general effect of the introduction of a baffle downstream of the cathode is seen in Fig. 9. The generally high level of discharge chamber losses reflected by these data is due to the unfavorable geometry and cathode flows used in early experiments. In the absence of a baffle (fig. 9a) the data cluster in the neighborhood of $2000 \mathrm{ev} /$ ion for all flow ratios. Introduction of a baffle (fig. 9b) significantly increases the dependence of discharge chamber losses on the flow ratio. These losses diminish at the low cathode to total flow ratios and increase at the high cathode to total flow ratios.

To determine the effect of baffle position on thrustor performance, tests, more detailed than those described above, were conducted with circular (solid) baffles of various diameters. The axial position could be changed during thrustor operation. The effect of baffle position at a propellant utilization efficiency of 85 percent is shown in Fig. 10. A minimum discharge chamber loss occurs at position zero, defined as the open end plane of the distributor pole piece. The minimum value decreases as the baffle diameter increases, the losses being least for a baffle diameter of 2.09 centimeters. Operation at 85 percent propellant utilization efficiency with a 1.27-centimeter diameter baffle could not be obtained at position zero.

The variation of discharge voltage with baffle position and size is shown in Fig. 10b. Again there is a critical point at position zero, in this case a maximum, for all baffle diameters which permitted operation at 85 percent propellant utilization efficiency. Thus an improvement by a change in baffle position in the discharge chamber losses generally corresponds to an increase in the discharge chamber voltage, and a shortening of expected lifetime.

The discharge chamber losses as a function of propellant utilization efficiency for the solid baffles at position zero are shown in Fig. 11. The maximum propellant utilization efficiency indicated by these curves increases as the baffle diameter increases. The maxima and minima of Figs. 10 and 11, with similar values obtained at position zero and 87.5 percent propellant utilization efficiency, are summarized in table I.

The effect of baffle diameter is further indicated in Fig. 12, which shows the voltage-emission current characteristics for each solid baffle at position zero. The characteristics shift toward higher voltage and lower. current as the baffle diameter is increased. All of the characteristics exhibit two regions. At lower currents, the current varies nearly linearly with voltage $\left(\frac{\partial^{2}\left(\Delta V_{I}\right)}{\partial\left(J_{E}\right)^{2}}=0\right)$. As the discharge current is increased, the rise in current for a given voltage increment becomes larger $\left(\frac{\partial^{2}\left(\Delta V_{I}\right)}{\partial\left(J_{E}\right)^{2}}<0\right)$. For the smaller baffles, a third region is noticeable at still higher discharge currents. The discharge characteristic passes through a point of inflection as the voltage increases to reach the third region $\left(\frac{\partial^{2}\left(\Delta V_{I}\right)}{\partial\left(J_{E}\right)^{2}}>0\right)$.

The first break point of the emission current characteristic separates two distinct modes of thrustor operation, region I and region II. Region I (linear region) of Fig. 12 corresponds to the lower portion of the curves of Fig. 11 and region II of Fig. 12 corresponds to the upper portion of the curves of Fig. 11 .

The rate of increase of the discharge chamber losses with propellant utilization efficiency is significantly smaller when the thrustor is operating in region I.

The first break point of emission current is determined graphically in Fig. 12 and is used to define a critical discharge chamber voltage for each baffle geometry. This critical voltage corresponds to a definite propellant utilization efficiency for each baffle configuration. The propellant utilization efficiencies determined in this manner are shown on each curve in Fig. 11. In all cases, these points fall on what is commonly called the knee of the curve. The slopes of these curves at the knee are roughly equal. Thus the first break point of emission current between regions I and II indicates some change in the mode of thrustor operation. Beyond this change, the propellant utilization efficiency approaches a saturation condition.

The annular open area between the distributor pole piece and the baffle, $A_{O}$, is defined as the area of the end plane of the distributor pole piece less the area of the solid baffle located in the pole piece end plane. The ratio of the emission current at the first break point to this open area is constant to within 11 percent for each of the baffles. Table II summarizes these parameters. They are not arbitrary as are some values of table:I, but are based on a definite change in discharge chamber operation.

\section{Baffle Modifications}

In addition to the various solid baffles, several other baffle types were tested. These included a 2.54centimeter diameter baffle with six holes, a baffle fabricated of wire cloth, and a baffle.having an annular 
open area as shown in Fig. 13. The six hole and annular baffles, when located in the end plane of the distributor pole piece, afforded the same pole piece open area, $A_{0}$. The wire cloth baffle provided nominally the same open area as the 1.96 centimeter diameter solid baffle.

Fig. 14 shows the discharge chamber losses and discharge voltage for the baffles of Fig. 13 as a function of baffle position for a propellant utilization efficiency of 85 percent. As in the case of solid baffles, the minimum discharge losses and maximum discharge voltages occur when the baffle is located in the open end plane of pole piece for each configuration. The annular design has lower discharge chamber losses and a higher discharge voltage than the six hole baffle despite the equality of the physical open area.

The exact reason for this variation in performance is not known. It is likely, however, that it results from either the different location of the baffle opening or a variation of effective electrical open area. The electrical open area is determined by the Debye shielding distance and affects the ion and electron current through the baffle openings. A comparison can be made between the characteristic dimensions of each baffle opening and a calculated Debye shielding distance by equation 1 .

$$
\ell_{0}=7.4 \times 10^{2} \sqrt{\mathrm{V} / \mathrm{n}} \mathrm{cm}
$$

The electron number density in the region of the baffle is probably larger than $10^{10} \mathrm{~cm}^{-3}$ (ref. 7) and the electron temperature is likely to be less than $15 \mathrm{~V}$, which is approximately the operating potential difference between the keeper and the cathode. The calculated Debye shielding distance using these values is of the order $0.3 \times 10^{-2} \mathrm{~cm}$, which is more than an order of magnitude smaller than the linear dimension at the opening in both baffle types. Therefore, it is likely that the effective electrical open area is very nearly the same for these two baffles. Thus, the difference in performance appears to be due to the different location of the baffle opening rather than a difference in the effective electrical open area.

The open area with the wire cloth baffle was 7.6 square centimeters. The characteristic dimension of a mesh opening, however, was approximately 0.016 centimeters, on the order of the Debye shielding dimension. Thrustor performance with the wire cloth baffle is compared with performance of several solid baffles at 85 percent propellant utilization efficiency and at position zero in table III. The performance of the wire cloth baffle is inconsistent when considered on the basis of the geometrical open area alone. If the baffles are compared on basis of diameter, the performance with wire cloth baffle is similar to the larger solid baffles. These results indicate that a perforated baffle with a sufficiently small characteristic length provides an obstruction similar to that of a solid baffle of the same diameter. This wire cloth baffle however has very little blockage of neutrals. Therefore, the primary effect of the baffle can be considered electrical in nature, affecting electron and ion currents through the open end plane of the distributor pole piece.

Endurance Tests

A 2000 hour SERT II endurance test was initiated during the baffle investigation. The thrustor had a sixhole baffle (fig. 13) located 0.47 centimeters downstream of the end plane of the distributor pole piece. The test was conducted in a 7.6-meter diameter vacuum facility capable of pressures on the low $10^{-7}$ torr range during thrustor operation.

The thrustor was operated at a discharge chamber voltage of 36 volts. The discharge chamber losses were nominally $250 \mathrm{ev} /$ ion at a propellant utilization efficiency of 85 to 87 percent. Neutral propellant flow through the cathode varied from 30 to 60 equivalent milliamperes. The ion beam current was maintained at 0.25 ampere at a net accelerating potential of +3000 volts.

The test was interrupted several times for inspection of the cathode surface. Examination of 70-power photographs showed only slight roughening of the cathode surface. No severe damage to the orifice was observed nor was there any evidence of a significant change in the thickness of the thoriated tungsten disk.

The test was finally terminated because of a cathode heater failure, probably due to flexing the heater lead during handling. Extrapolation of the results indicate cathode tip lifetimes on the order of 10000 hours can easily be obtained.

\section{Neutral Propellant Flows}

A thrustor similar to that which was endurance tested was used to determine the effect of neutral propellant flow on thruster operation. The cathode flow was held constant while the main flow was varied and thrustor performance was documented. The propellant utilization efficiency was varied by changing the ion beam current at a constant neutral flow. The main propellant flows were repeated to within \pm 2.5 percent.

The effect of the various flow combinations is seen in Fig. 15. The variation of discharge chamber losses with propellant utilization efficiency is somewhat insensitive to the neutral propellant flow. The general level of the discharge chamber losses at a given propellant utilization efficiency as well as the maximum propellant utilization efficiency is much stronger function of baffle geometry and location (figs. 10 and 11) than the main neutral propellant flow variation within the range of Fig. 15.

The main peopellant flow affects thrustor performance less than the cathode propellant flow. At a propellant utilization efficiency of 85 percent, the discharge chamber losses vary less than $15 \mathrm{ev} /$ ion for a total propellant flow change of approximately 54 equivalent milliamperes.

The effect of cathode propellant flow on the discharge chamber losses at near constant main flow is shown in figure 16. The discharge chamber losses increase by more than $50 \mathrm{ev} /$ ion for propellant flow increases on the order of 30 equivalent milliamperes. The curves of Fig. 16 exhibit a minimum for low main propellant flows but are monotonic for the higher main propellant flows.

The effect of propellant flows on the discharge chamber voltage at constant propellant utilization 
efficiency is shown in Figs. 17 and 18. An increase in either propellant flow causes a decrease in the voltage. However, comparison of Figs. 17 and 18 shows the discharge voltage to be a stronger function of the cathode flow. Fig. 18 also shows a point of inflection for the low main propellant flow. This critical point occurs at the same cathode flow as the discharge chamber loss minimum in Fig. 16. As this mimimum disappears with increasing main propellant flow (fig. 16), the sharp increase in discharge voltage at the lower cathode flows (fig. 18) becomes less noticeable and is nonexistent for the highest main propellant flow.

The interesting result of these data is that they generate a single curve of discharge chamber loss versus propellant utilization efficiency for each discharge voltage (fig. 19). For a given thrustor geometry and a constant discharge voltage, thrustor operation is restricted to a single curve, regardless of the absolute value or ratio of the propellant flows. Thus, the variation of propellant flows can determine the point on the proper curve of Fig. 19 at which the thrustor operates, but a change in geometry, such as baffle location or position, probably causes a shift of the constant voltage curve giving rise to the significant change in operation reflected by Figs. 10 and 11.

\section{Summary of Results}

Initial tests determined that a hollow cathode could be used in the SERT II thrustor. A baffle was required downstream of the cathode to make thrustor operation competitive with that of a thermionic cathode thrustor. Operation without the baffle resulted in high discharge chamber losses and low propellant utilization efficiencies. Slight or no modification of previously optimized thrustor parameters, such as magnetic field strength and shape was found to be necessary. Minimum values of discharge chamber losses and maximum voltage occurred when the baffle was located at the end plane of the distributor pole piece. Increasing the baffle diameter up to 2.09 centimeters caused a decrease in the discharge losses and an increase in the discharge voltage.

Examination of the volt-emission current characteristics for several solid baffles determined a point at which the mode of thrustor operation changed significantly. This change occurred at nominally the same value of emission current density at the annular open area between the distributor pole piece and the baffle for all baffles tested. The propellant utilization efficiency began to saturate at this point.

The effect of main and cathode neutral propellant flow on thrustor performance was investigated. For the range of flows investigated, an increase in either main or cathode propellant flow decreased the discharge chamber voltage and generally increased the discharge chamber losses. The cathode neutral flow variation caused the larger changes in thrustor operating parameters. However, the differences in thrustor operation for all flow combinations tested were much smaller than the changes in operating conditions due to baffle modifications.
If either main or cathode neutral flows were increased at a constant discharge chamber voltage, the propellant utilization efficiency and the discharge chamber losses increased. The result was that a single curve of discharge chamber losses versus propellant utilization efficiency described operation of a given thrustor configuration at a constant discharge chamber voltage.

Finally, a flight model thrustor was endurance tested for more than 2000 hours. The thrustor operated at approximately $250 \mathrm{ev} / \mathrm{ion}$ at a propellant utilization efficiency of 85 to 87 percent and discharge chamber voltage of 36 volts. The ion beam current was 0.25 ampere at a net accelerating potential of +3000 volts. This test provided projected lifetimes in excess of 10000 hours.

\section{Symbols}

$A_{0} \quad$ pole piece open area, area of end plane of distributor pole piece less area of baffle, $\mathrm{cm}^{2}$

$\mathrm{E}_{\mathrm{I}}$ discharge chamber losses, ev/ion

$\ell_{0} \quad$ Debye shielding distance, $\mathrm{cm}$

$J_{B} \quad$ ion beam current, amps

$\mathrm{J}_{\mathrm{E}} \quad$ cathode emission current, amps

$\mathrm{J}_{\mathrm{OK}}$ cathode neutral propellant flow, equivalent milliamperes

JOM main neutral propellant flow, equivalent milliamperes

JoT total neutral propellant flow, equivalent milliamperes

n electron number density, $\mathrm{cm}^{-3}$

$\eta_{\mathrm{u}} \quad$ propellant utilization efficiency, percent

$\Delta V_{I}$ ion discharge chamber voltage, volts

$\vec{V} \quad$ average electron temperature, electron volts

References

1. Bechtel, R. T., "Discharge Chamber Opt imization of the SERT II Thrustor," Paper No. 67-668, Sept. 1967, AIAA, New York.

2. Kerslake, W. R., Byers, D. C., and Staggs, J. F., "SERT II Experimental Thrustor System," Paper No. 67-700, Sept. 1967, AIAA, New York.

3, Reader, P. D. and Pawlik, E. V., "Cathode Durability Tests in Mercury Electron-Bombardment Ion Thrustors, "TN D-4055, July 1967, NASA, Cleveland, Ohio.

4. Eckhardt, W. O., Hagen, G., Snyder, J. A., and Knechtli, R. C., "High-Temperature Liquid- 
Mercury Cathodes for Ion Thrustors, "QR-2 (NASA CR-81690), Nov. 1966, Hughes Research Labs. , Malibu, Calif.

5. Rawlin, V. K. and Pawlik, E. V., "A Mercury Plasma-Bridge Neutralizer," Paper No. 67-670, Sept. 1967, ALAA, New York.
6. Reader, P. D., "Durability Tests of Mercury Electron-Bombardment Ion Thrustors, " Paper No. 66-231, Mar. 1966, AIAA, New York.

7. Strickfaden, W. B. and Geiler, K. L., "Probe Measurements of the Discharge in an Operating Electron Bombardment Engine," TR-32-417 (NASA CR-50623), Apr. 1963, Jet Propulsion Lab., Pasadena, Calif.

\begin{tabular}{|c|c|c|c|c|c|}
\hline $\begin{array}{l}\text { Baffle } \\
\text { Diam. } \\
\text { cm }\end{array}$ & $\begin{array}{c}\Delta V_{\mathbf{I}} \\
\text { at } \eta_{\mathrm{u}}=85 \% \\
\text { Volts }\end{array}$ & $\begin{array}{c}\mathbf{E}_{\mathrm{I}} \\
\text { at } \eta_{\mathbf{u}}=85 \% \\
\text { ev } / \text { ion }\end{array}$ & $\begin{array}{l}\text { Approx. } \\
\underset{\%}{\operatorname{Max}} \eta_{\mathbf{u}}\end{array}$ & $\begin{array}{c}\Delta V_{I} \\
\text { at } \eta_{\mathrm{u}}=87.5 \% \\
\text { Volts }\end{array}$ & $\begin{array}{c}E_{I} \\
\text { at } \eta_{\mathrm{u}}=87.5 \% \\
\text { ev } / \text { ion }\end{array}$ \\
\hline 1.27 & \multicolumn{2}{|c|}{ Not obtained } & 78 & \multicolumn{2}{|c|}{ Not obtained } \\
\hline 1.82 & 33.8 & 295 & 91 & 34.6 & 345 \\
\hline 1.96 & 34.7 & 230 & 92 & 35.7 & 258 \\
\hline 2.09 & 36.5 & 203 & 94 & 37.4 & 215 \\
\hline
\end{tabular}

Table I. Summary of Critical Values of Thrustor Discharge Parameters for Various Baffles Located at Position Zero

\begin{tabular}{|c|c|c|c|c|c|c|}
\hline $\begin{array}{c}\text { Baffle } \\
\text { Diam. } \\
\mathrm{cm}\end{array}$ & $\begin{array}{c}\text { Open } \\
\text { Area of } \\
\text { Pole Piece } \\
\mathrm{A}_{\mathrm{O}}, \mathrm{cm}^{2}\end{array}$ & $\begin{array}{c}\text { Emission } \\
\text { Current } \\
\text { at } 1 \text { st Break- } \\
\text { point } \\
\mathrm{J}_{\mathrm{E}} \text {, amps }\end{array}$ & $\begin{array}{l}\text { Critical } \\
\text { Discharge } \\
\text { Voltage } \\
\text { at 1st Break- } \\
\text { point } \\
\text { Volts }\end{array}$ & $\begin{array}{c}\text { Propellant } \\
\text { Utilization } \\
\text { Efficiency } \\
\text { at 1st Break- } \\
\text { point } \\
\%\end{array}$ & $\begin{array}{l}\text { Discharge } \\
\text { Chamber } \\
\text { Losses } \\
\text { at 1st Break- } \\
\text { point } \\
\text { ev/ion }\end{array}$ & $\begin{array}{c}\mathrm{J}_{E} / A_{0} \\
\operatorname{amps} / \mathrm{cm}^{2}\end{array}$ \\
\hline 1.27 & 9.23 & 1.74 & 27.5 & 68.3 & 325 & 0.188 \\
\hline 1.81 & 7.93 & 1.70 & 33.7 & 84.6 & 287 & 0.214 \\
\hline 1.96 & 7.48 & 1.46 & 37.2 & 89.0 & 262 & 0.193 \\
\hline 2.09 & 7.08 & 1.22 & 39.4 & 90.5 & 245 & 0.172 \\
\hline
\end{tabular}

Table II. Summary of Critical Values of Thrustor Discharge Parameters Based on First Emission Current Breakpoint

\begin{tabular}{|c|c|c|c|}
\hline $\begin{array}{l}\text { Baffle } \\
\text { Diam. } \\
\text { cm }\end{array}$ & $\begin{array}{l}\text { Pole Piece } \\
\text { Open } \\
\text { Area, } A_{0} \\
\mathrm{~cm}^{2}\end{array}$ & $\begin{array}{c}\text { Discharge } \\
\text { Voltage } \\
\Delta V_{I} \\
\text { Volts }\end{array}$ & $\begin{array}{c}\text { Discharge } \\
\text { Chamber } \\
\text { Losses } \\
\mathrm{E}_{\mathrm{I}} \\
\text { ev/ion }\end{array}$ \\
\hline $\begin{array}{l}2.54 \\
\text { Solid }\end{array}$ & 5.44 & 42.5 & 205 \\
\hline $\begin{array}{l}2.09 \\
\text { Solid }\end{array}$ & 7.1 & 36.5 & 200 \\
\hline $\begin{array}{l}1.96 \\
\text { Solid }\end{array}$ & 7.5 & 34.7 & 230 \\
\hline $\begin{array}{l}2.40 \\
\text { Wire Cloth }\end{array}$ & 7.6 & 42.0 & 205 \\
\hline
\end{tabular}


.

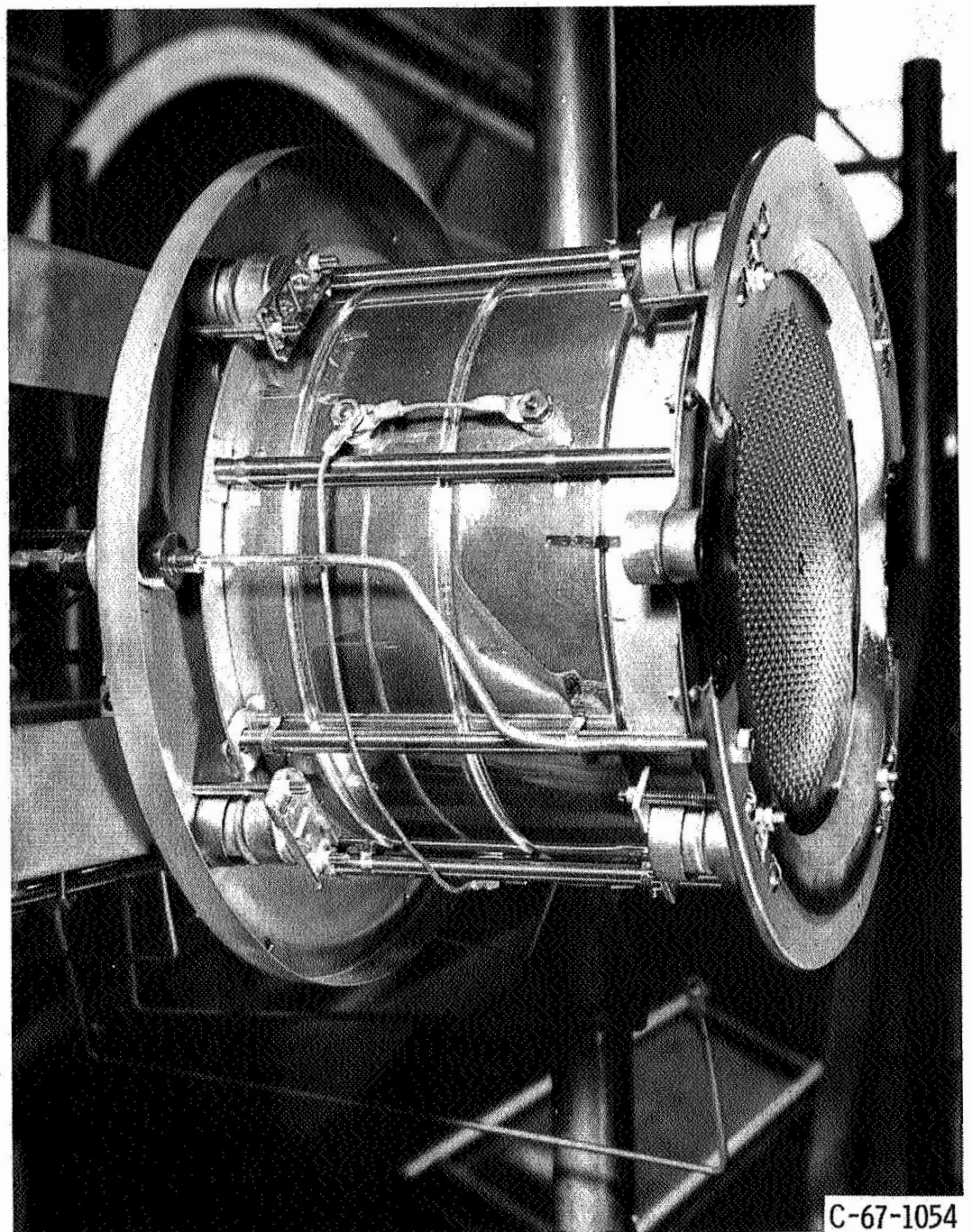

Figure 1. - 15-cm diameter Kaufman thruster. 
唄

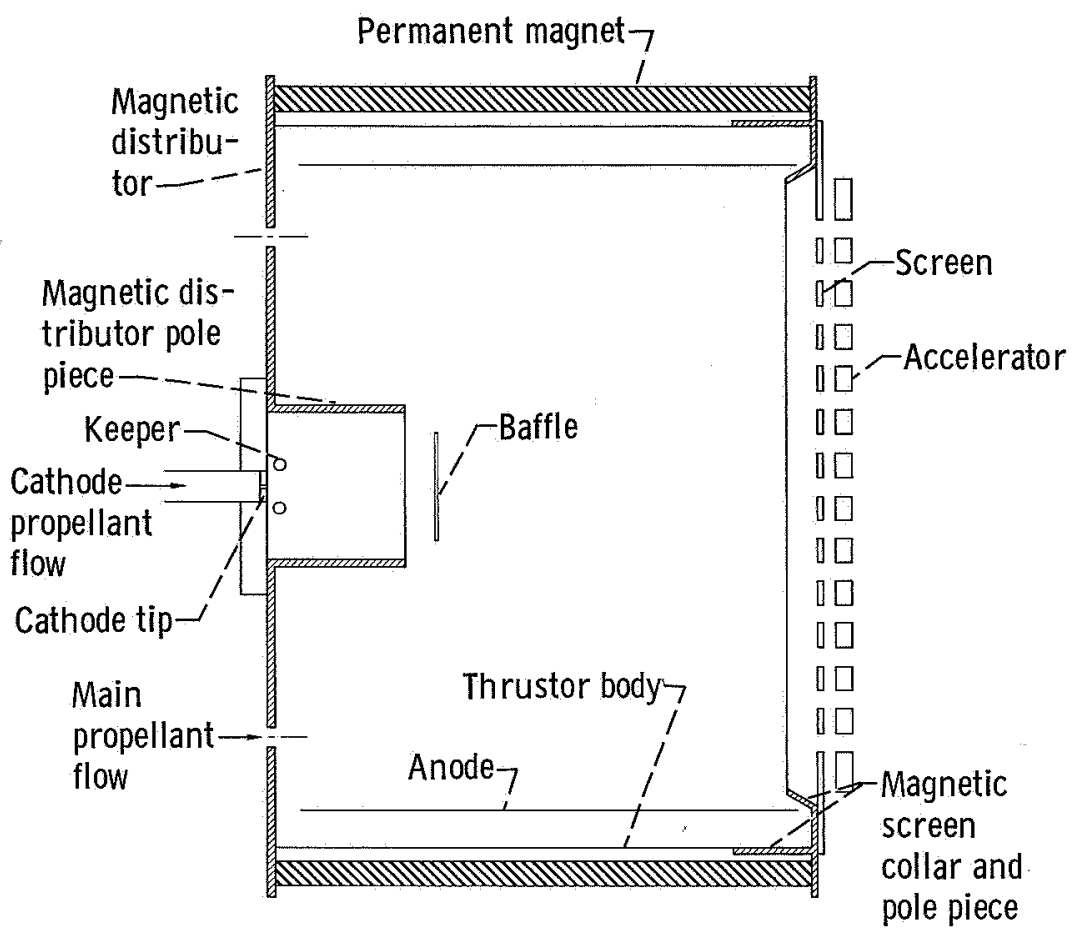

Figure 2. - Sketch of 15-cm diameter Kaufman thruster. 


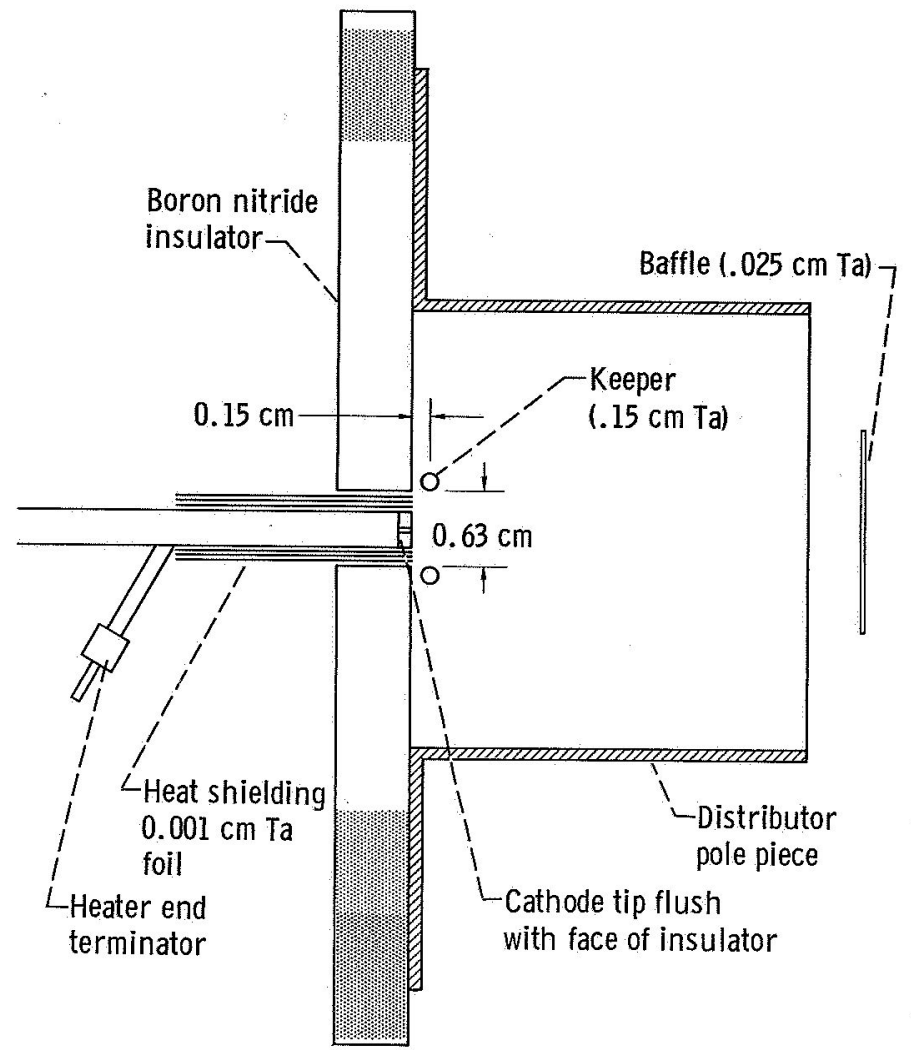

(a) Sketch of component arrangement.

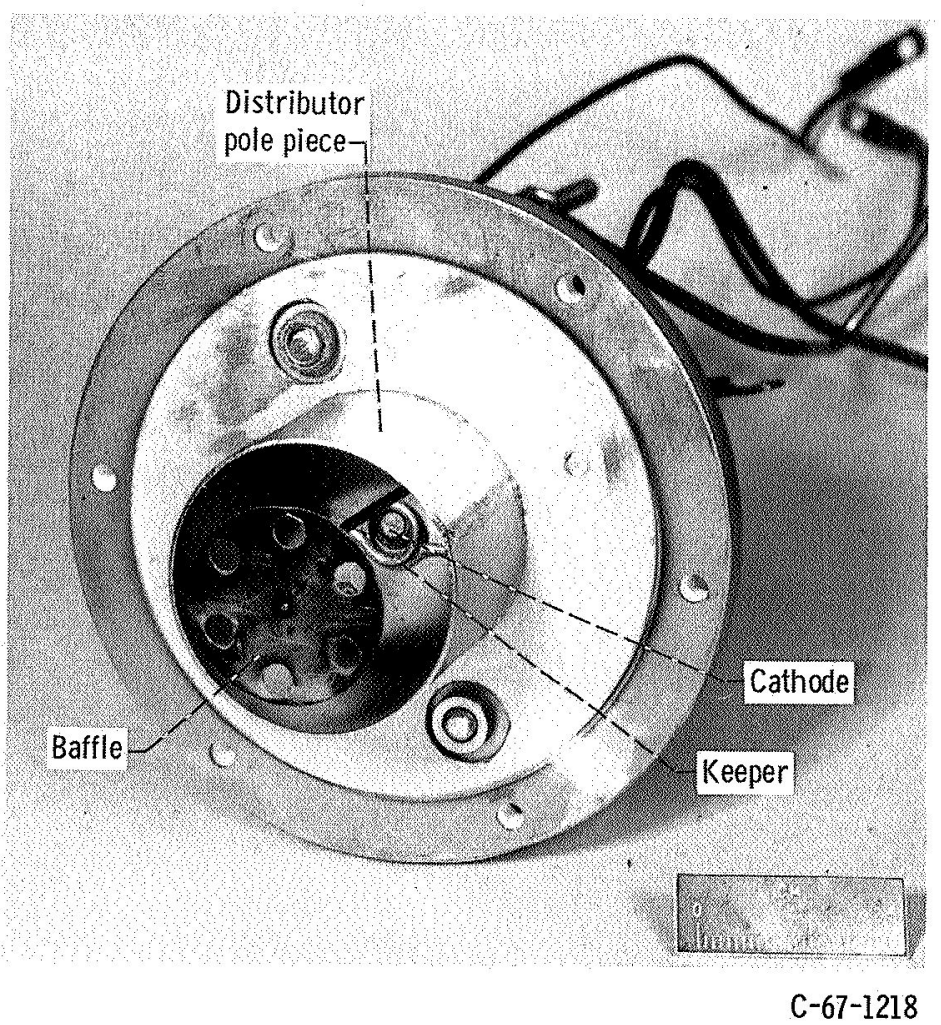

(b) Photograph of experimental configuration.

Figure 3. - Cathode - distributor pole piece assembly. 


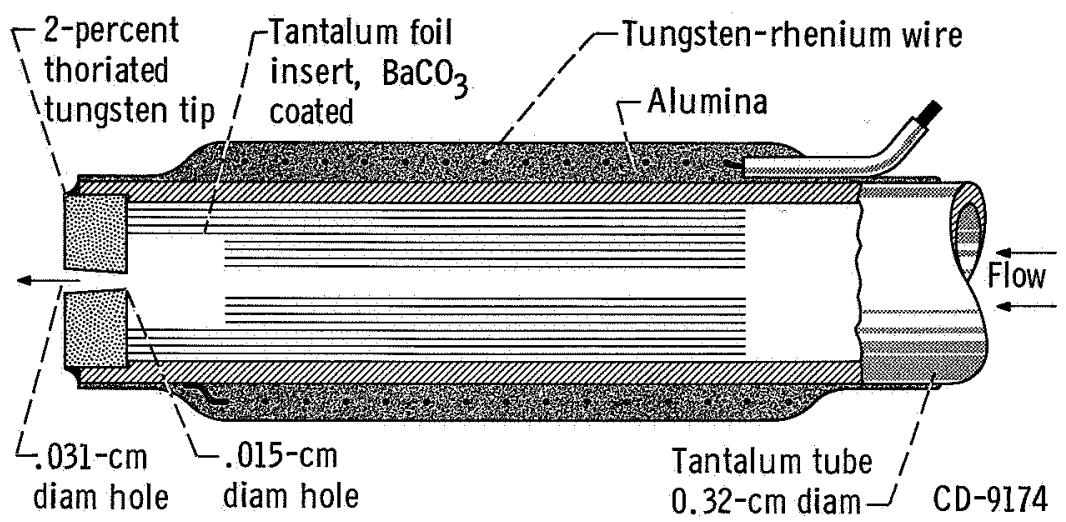

Figure 4. - Sketch of hollow cathode tip.

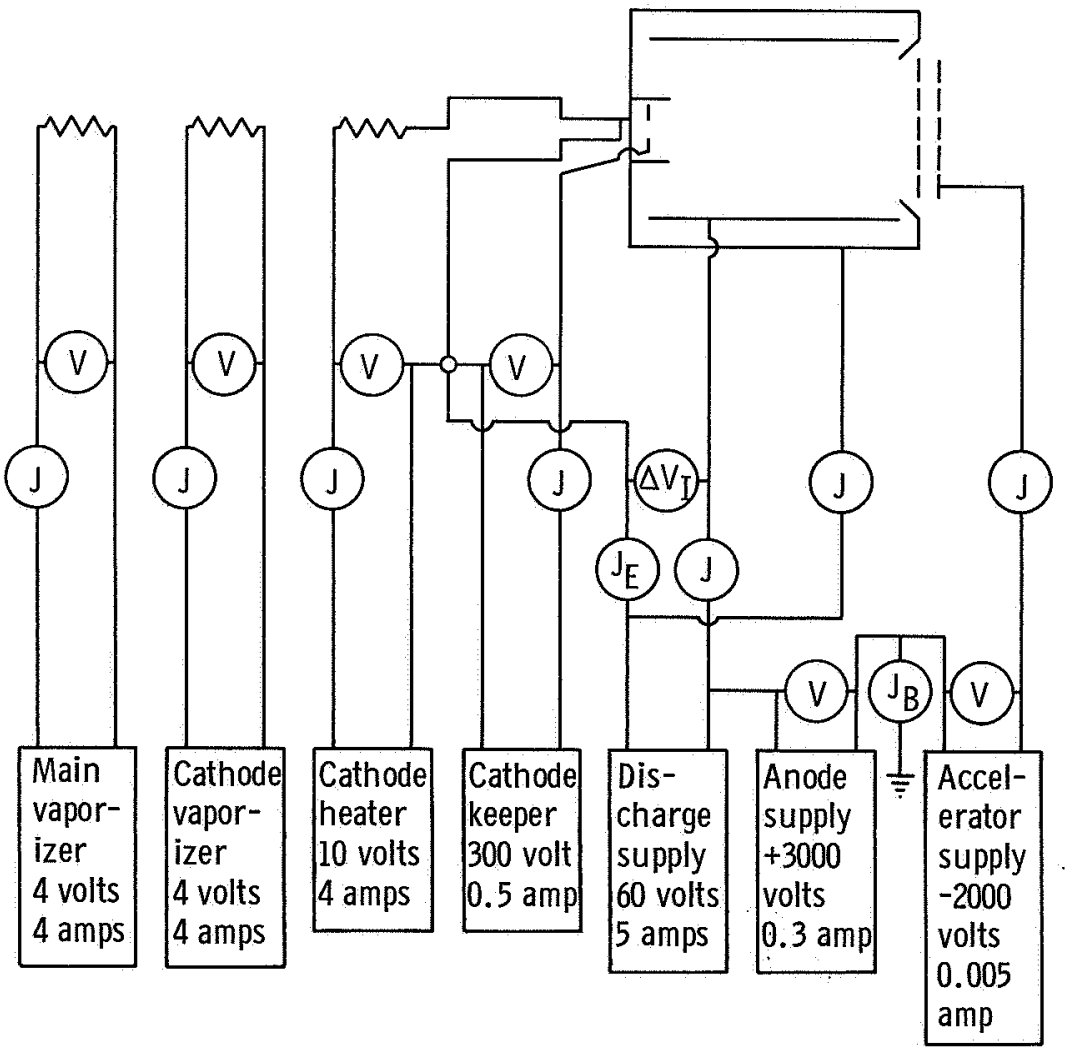

Figure 5. - Electrical wiring schematic. 


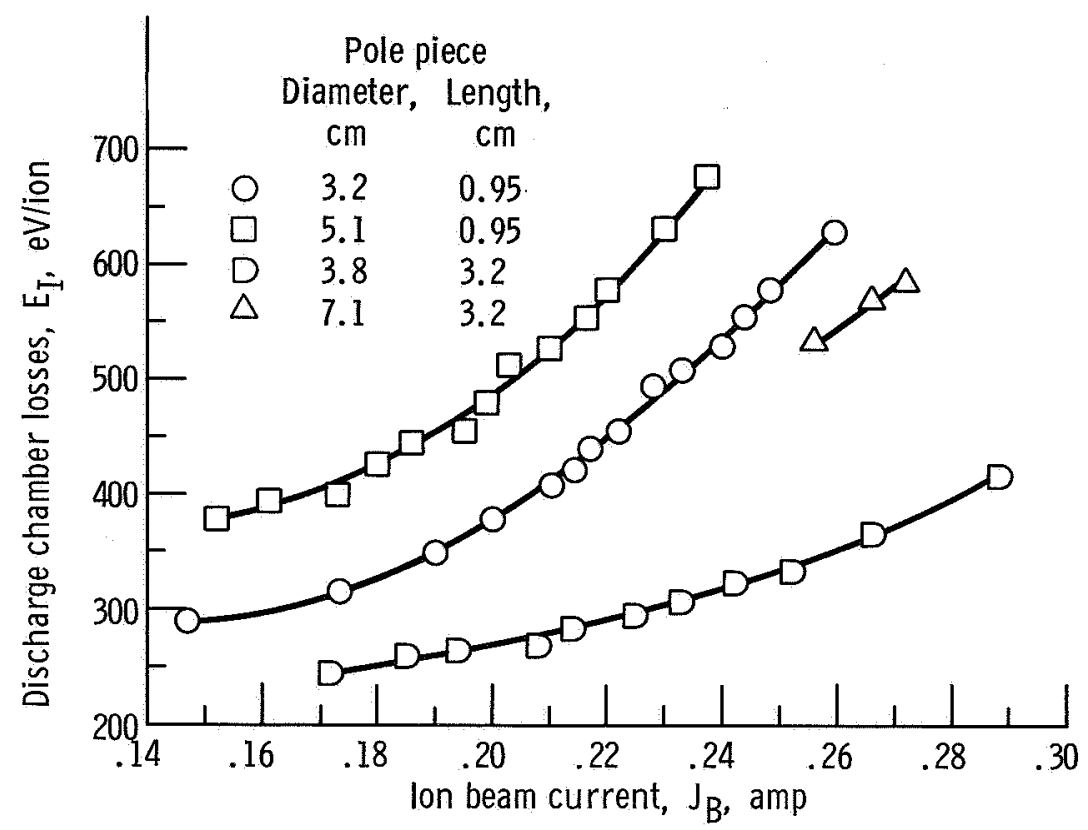

Figure 6. - Discharge chamber losses as a function of ion beam current for several distributor pole pieces. 


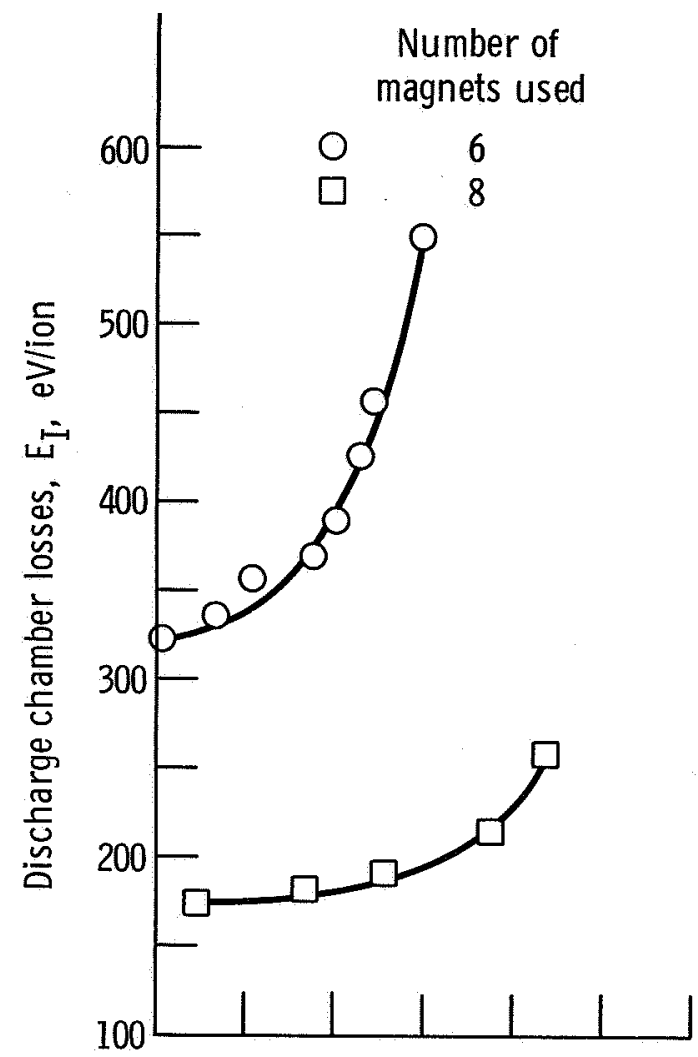

(a) Discharge chamber losses.

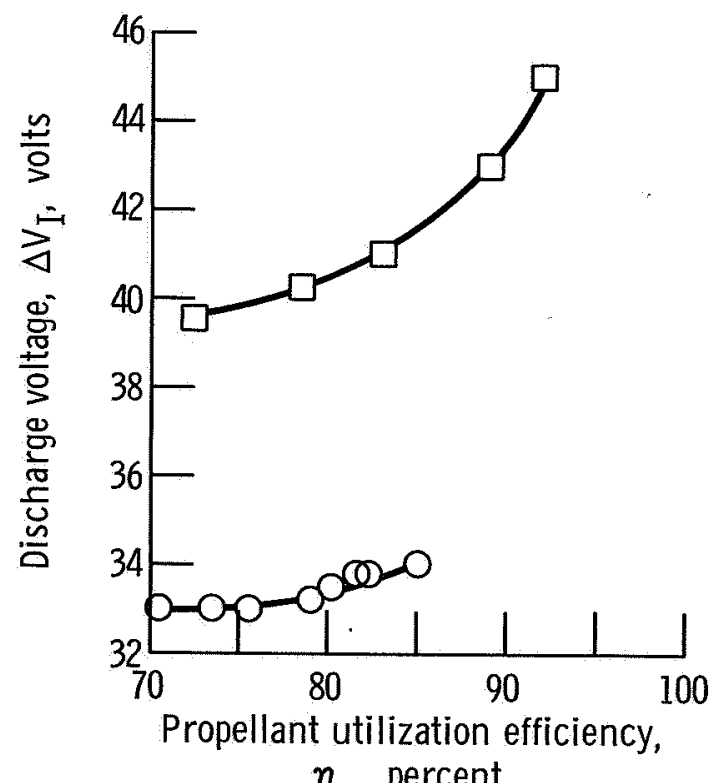

(b) Discharge chamber voltage.

Figure 7. - Effect of number of permanent magnets on thrustor performance. 


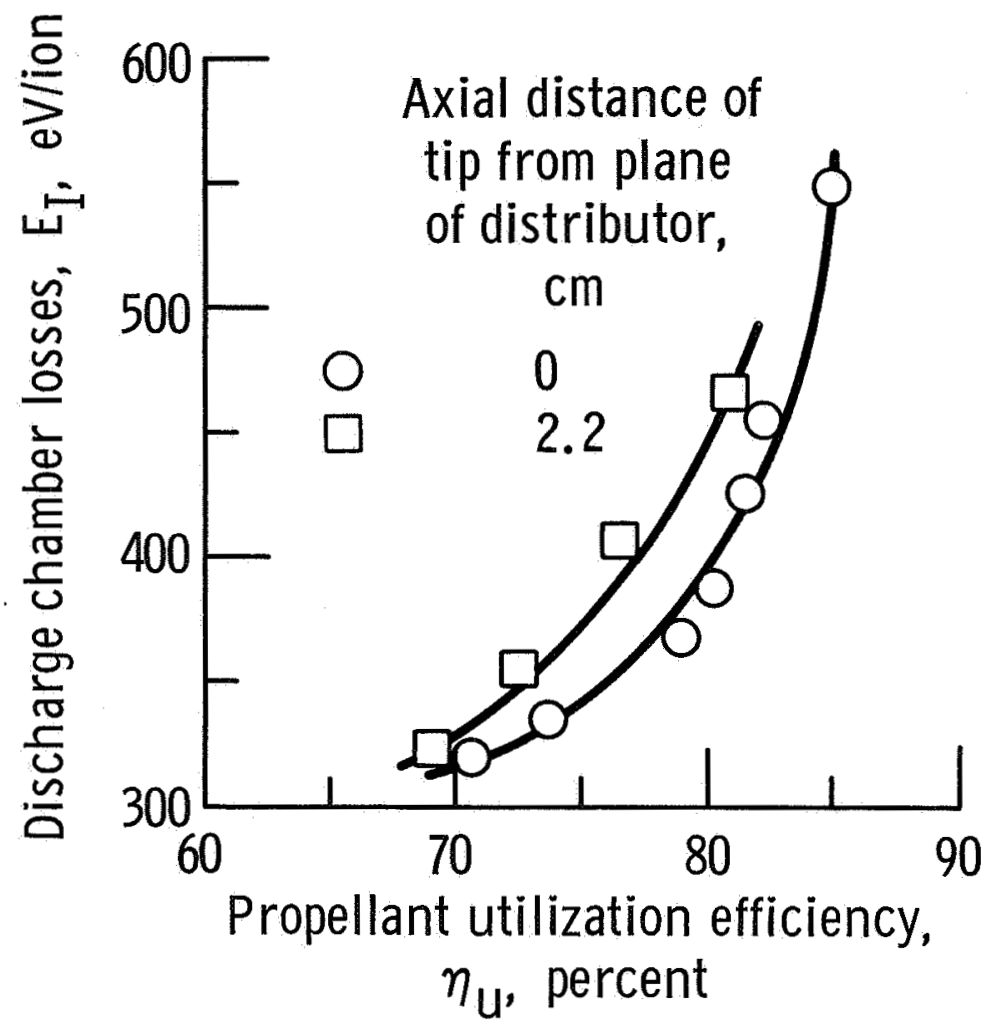

Figure 8. - Effect of axial shift of cathode tip. Baffle diameter, $2.54 \mathrm{~cm}$. Baffle located 0.64 $\mathrm{cm}$ from pole piece. 


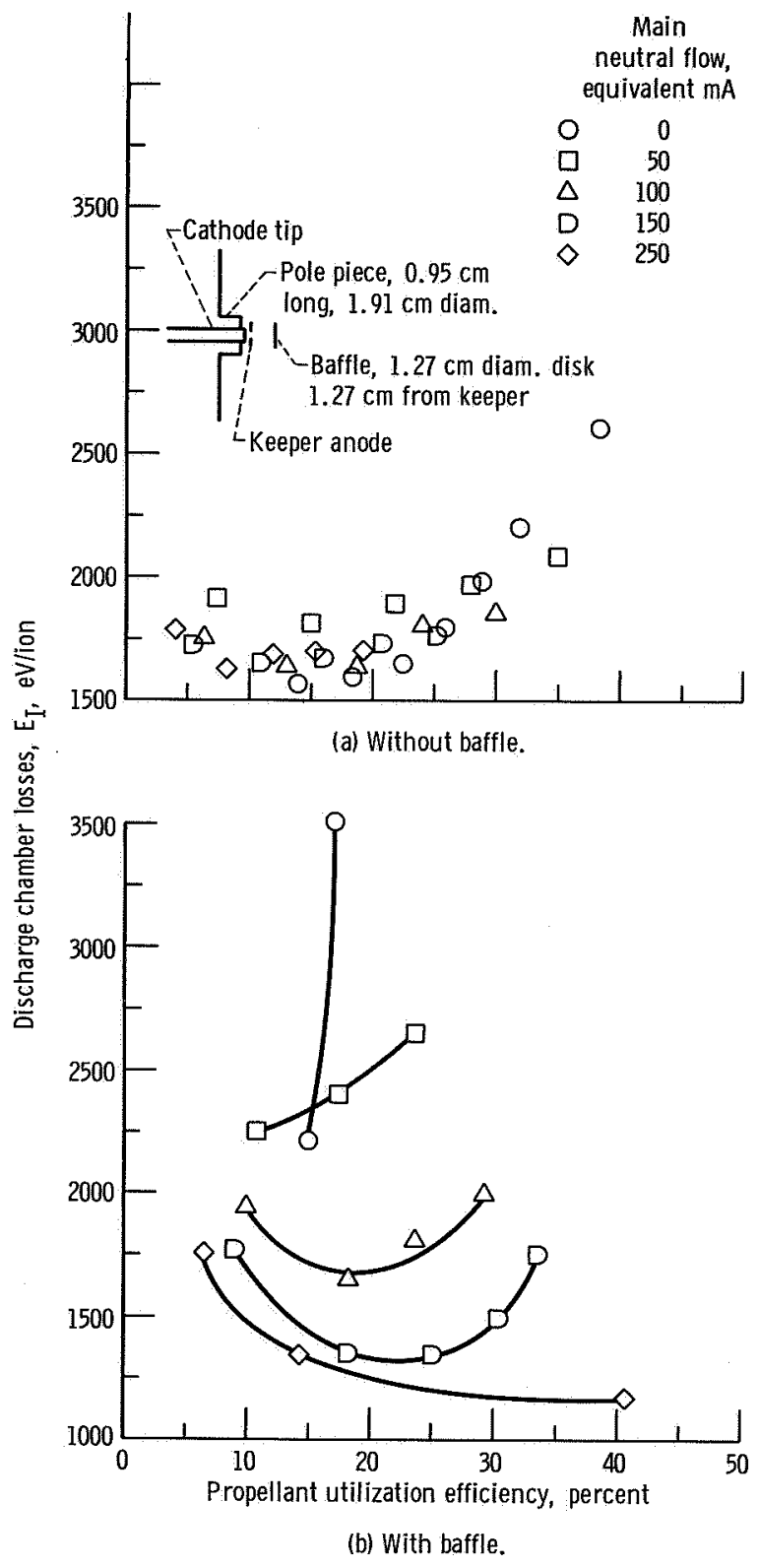

Figure 9. - Discharge chamber losses as a function of propellant utilization efficiency with and without baffle. Cathode neutral flow, 0.20 equivalent amperes. 


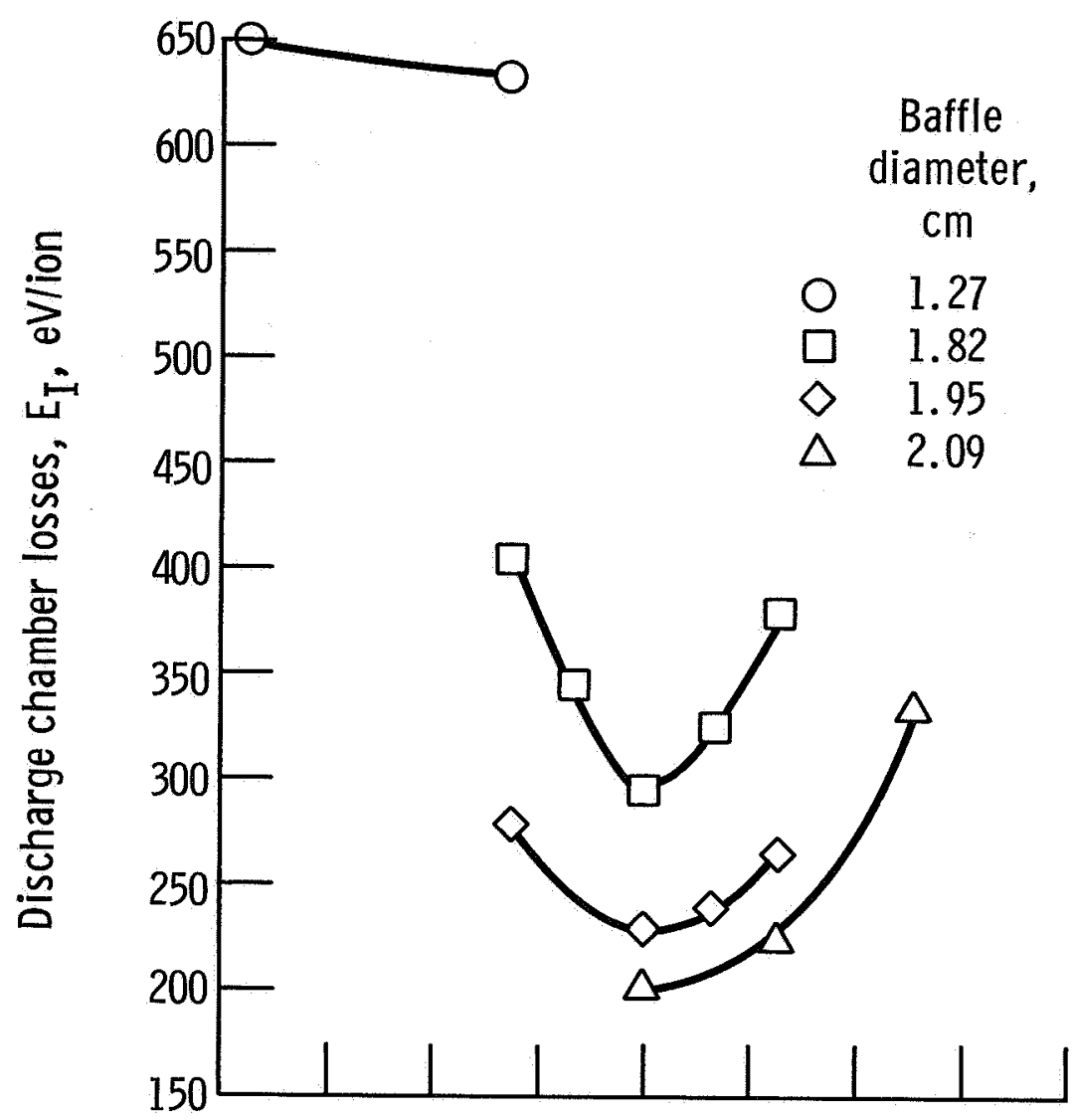

(a) Discharge chamber losses.

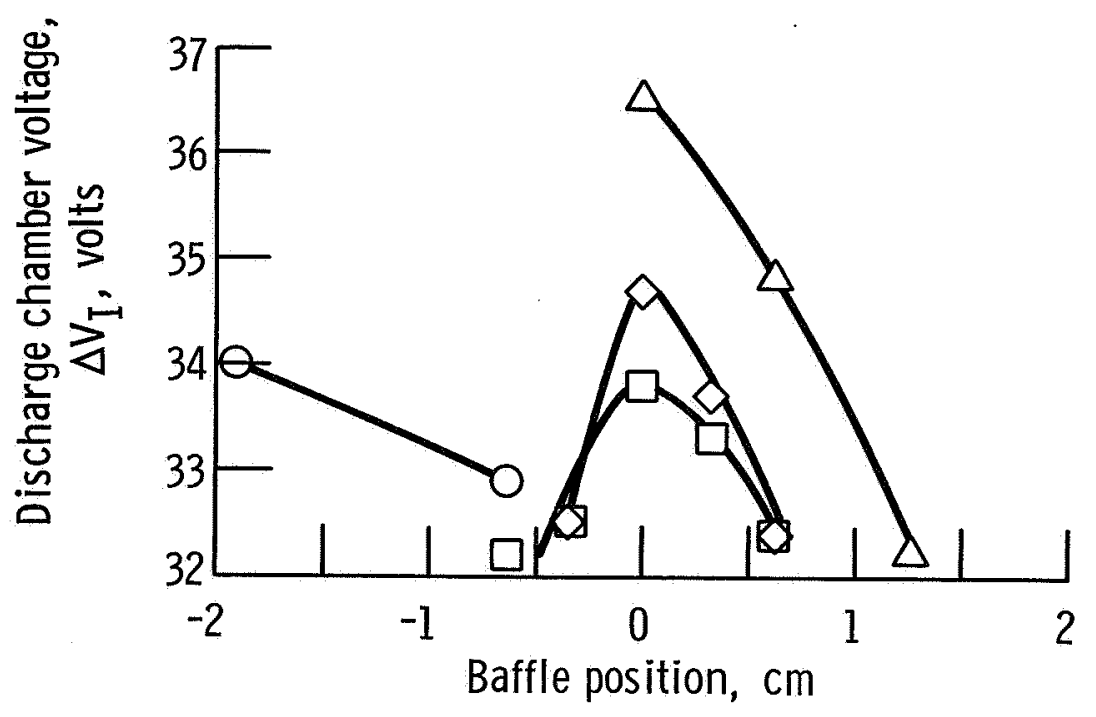

(b) Discharge chamber voltage.

Figure 10. - Thrustor performance as a function of baffle position. Propellant utilization efficiency, $\eta_{u}, 85$ percent. 


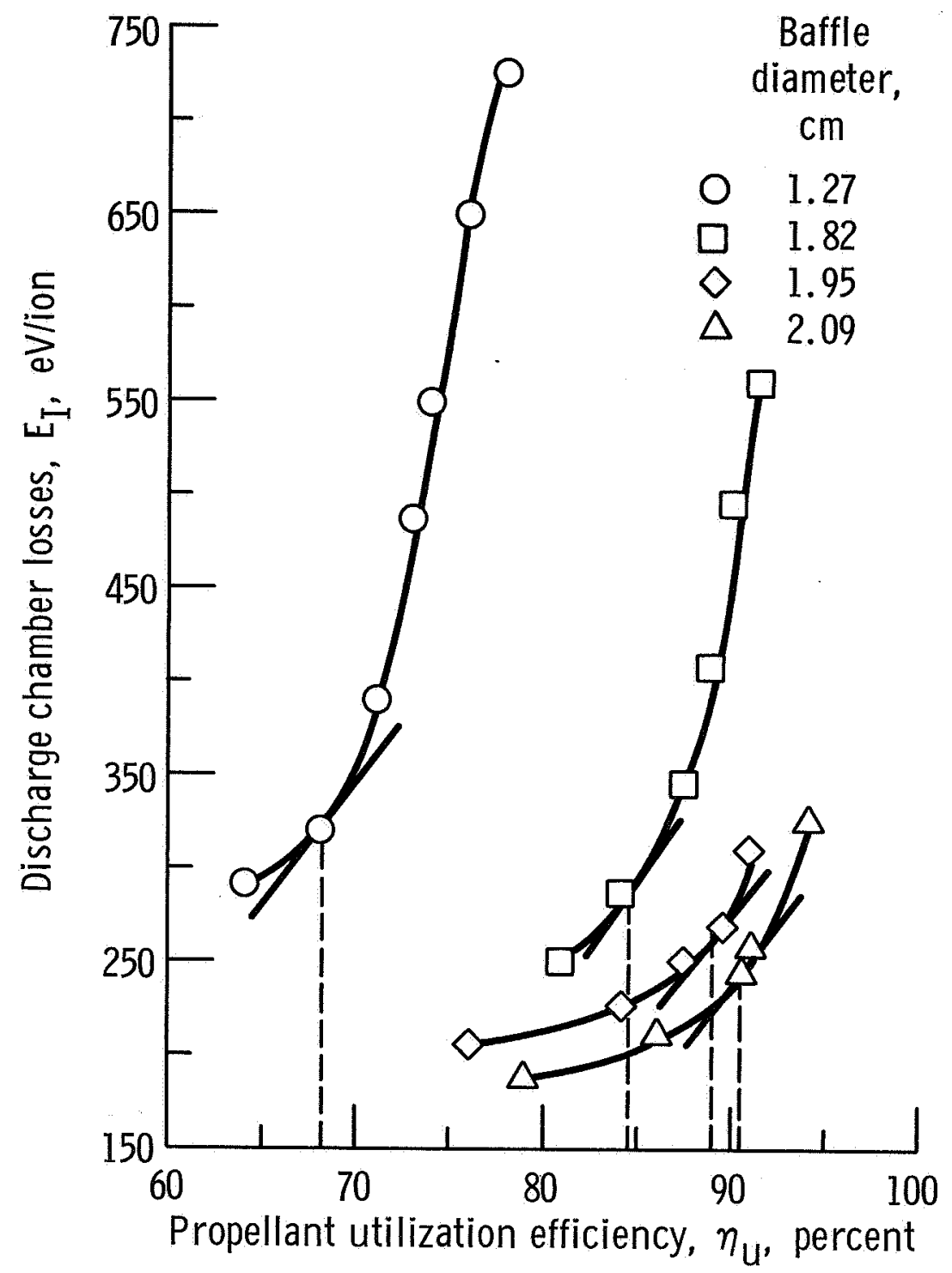

Figure 11. - Discharge chamber losses as a function of propellant utilization efficiency for solid baffles located at position zero. 
令

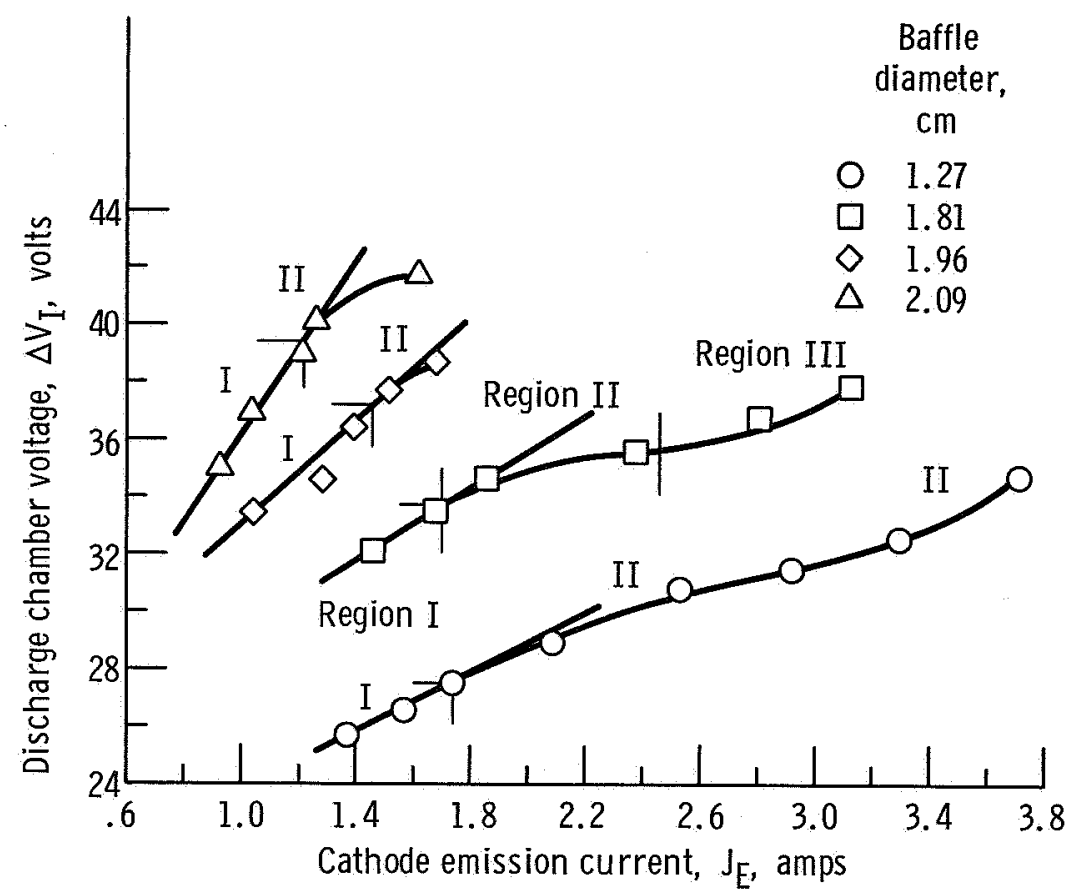

Figure 12. - Discharge voltage-emission current characteristics for solid baffles located at position zero. $\left(J_{E}\right.$ Corrected for parallel current path through thruster body shown in fig. 5.1 


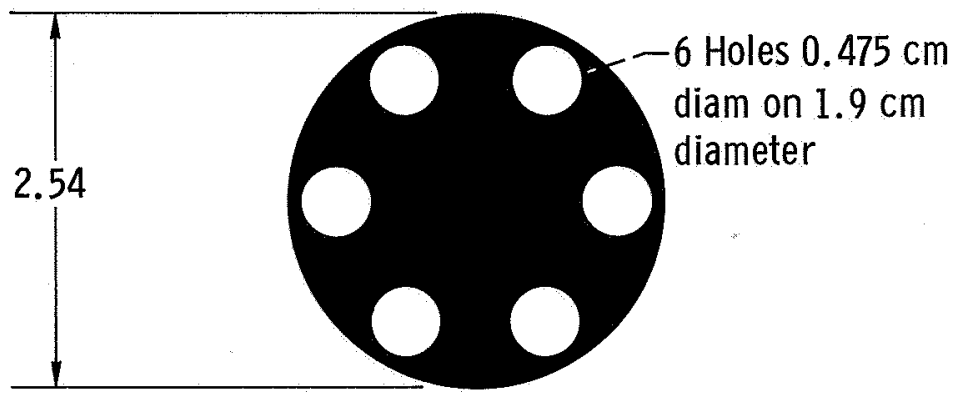

6 Hole baffle open area $=6.0 \mathrm{~cm}^{2}$

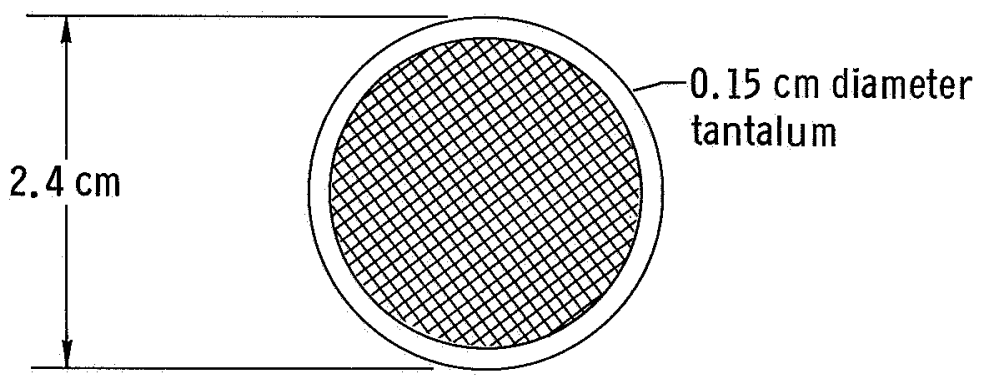

Wire cloth baffle wire diameter, $0.077 \mathrm{~mm}$ mesh, $42 / \mathrm{cm}$ 46 percent open area $=7.6 \mathrm{~cm}^{2}$

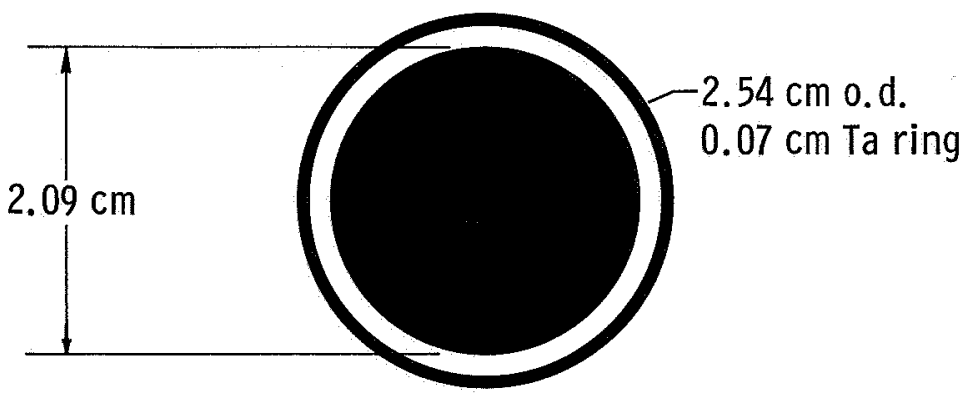

Annular baffle open area $=6.0 \mathrm{~cm}^{2}$

Figure 13. - Open area baffles tested (open area based on 3.8-cm diameter pole piece.) 


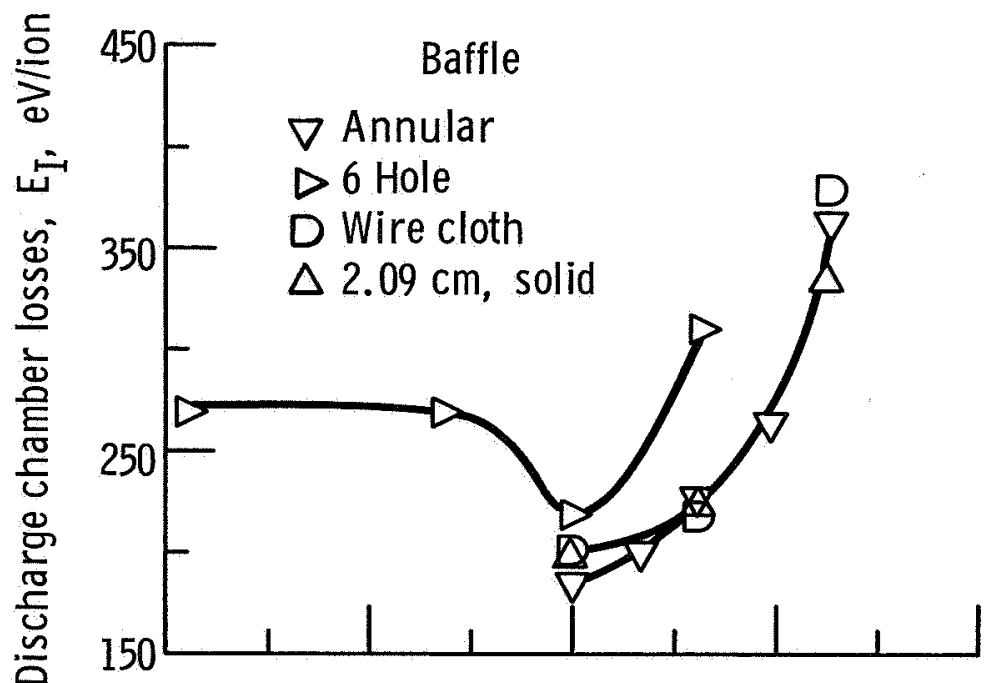

(a) Discharge chamber losses.

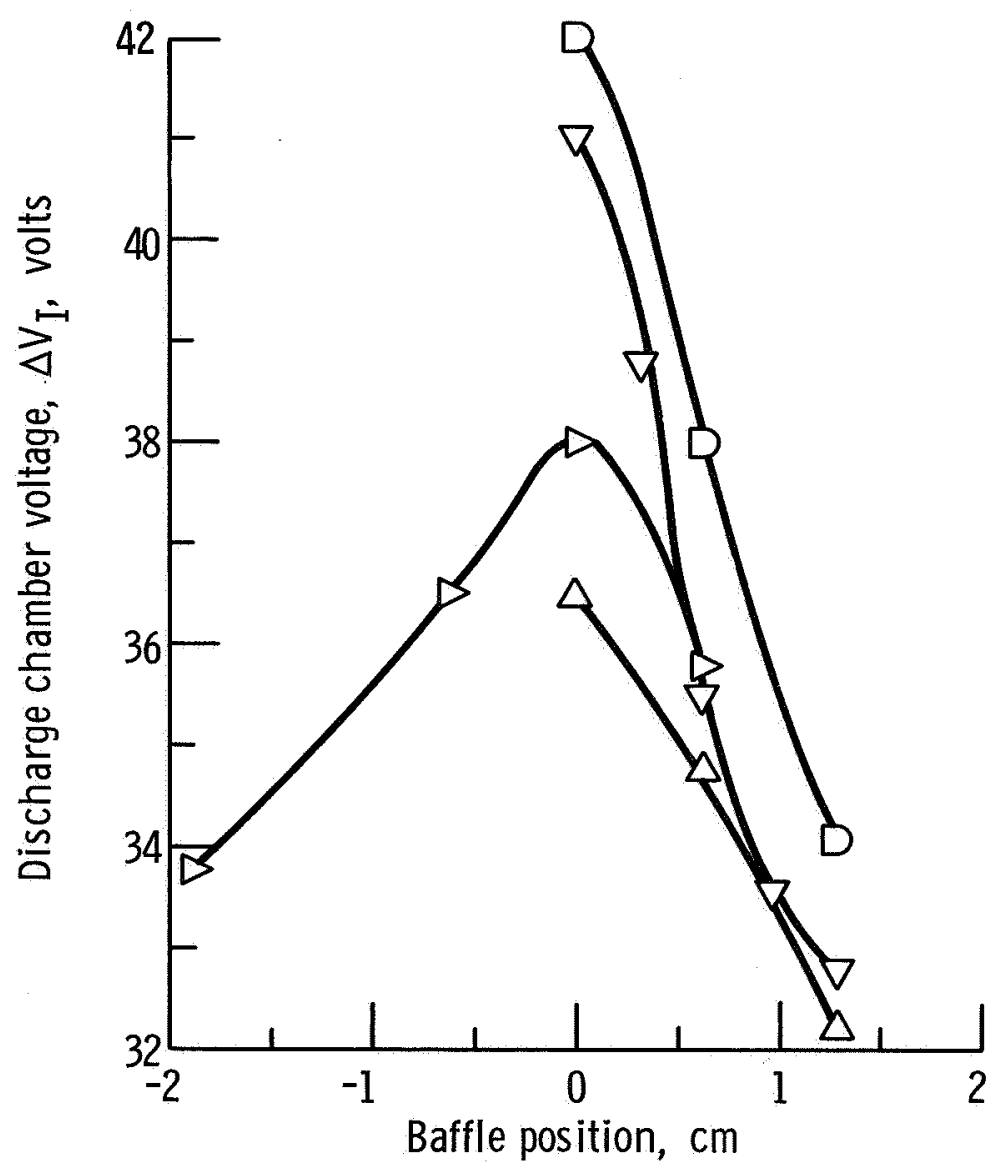

(b) Discharge chamber voltsge.

Figure 14. - Thruster performance as a function of baffle position. Propellant utilization efficiency, $\eta_{\mathrm{u}}, 85$ percent. 


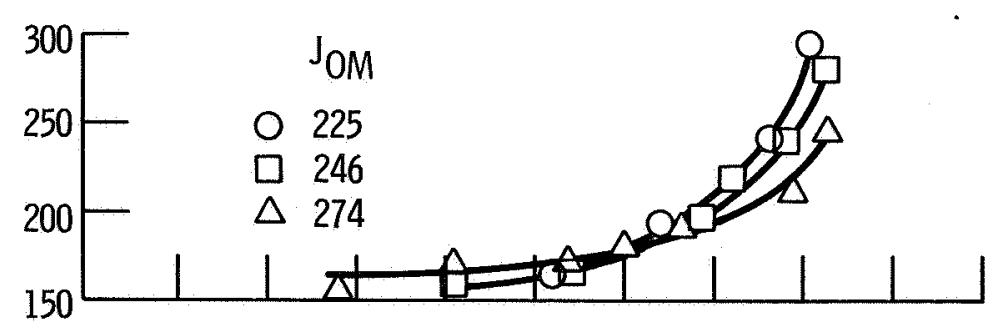

(a) $\mathrm{J}_{\mathrm{OK}}=39 \mathrm{~mA}$.

品

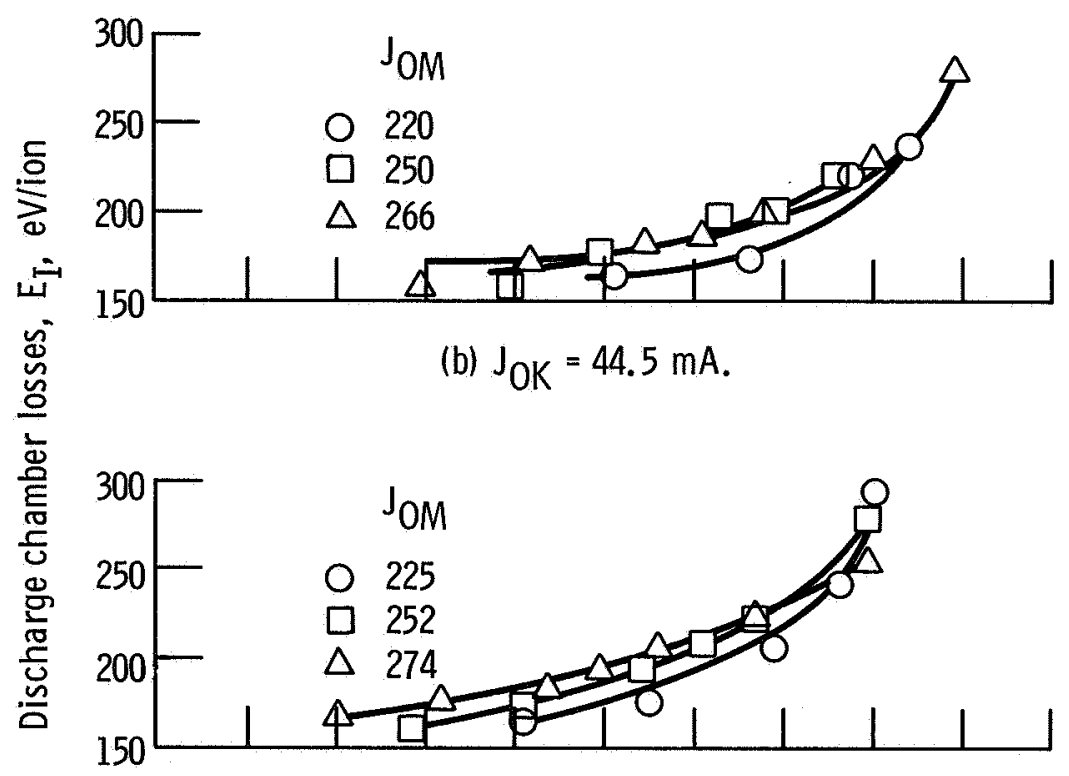

(c) $\mathrm{J}_{\mathrm{OK}}=59.5 \mathrm{~mA}$.

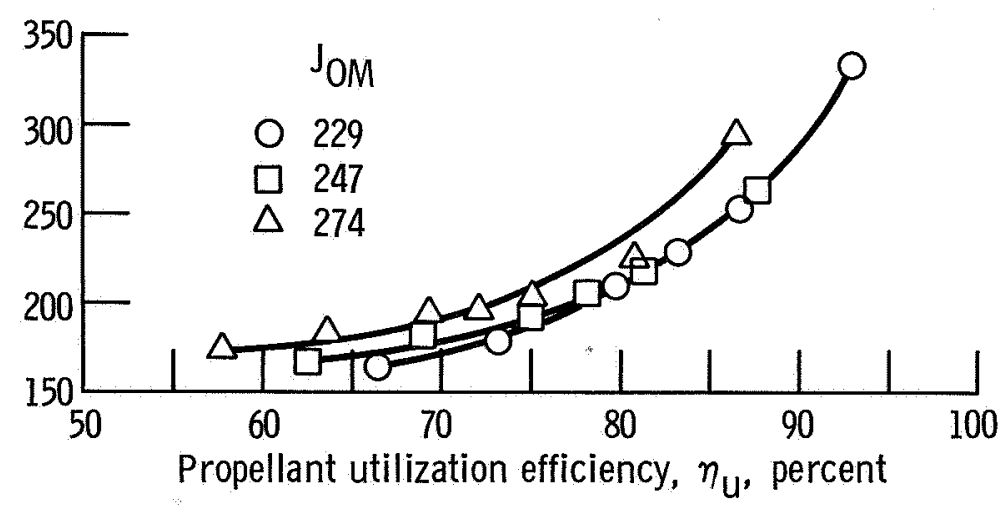

(d) $\mathrm{J}_{\mathrm{OK}}=72.5 \mathrm{~mA}$.

Figure 15. - Discharge chamber losses for various combinations of cathode and main propellant flow. 


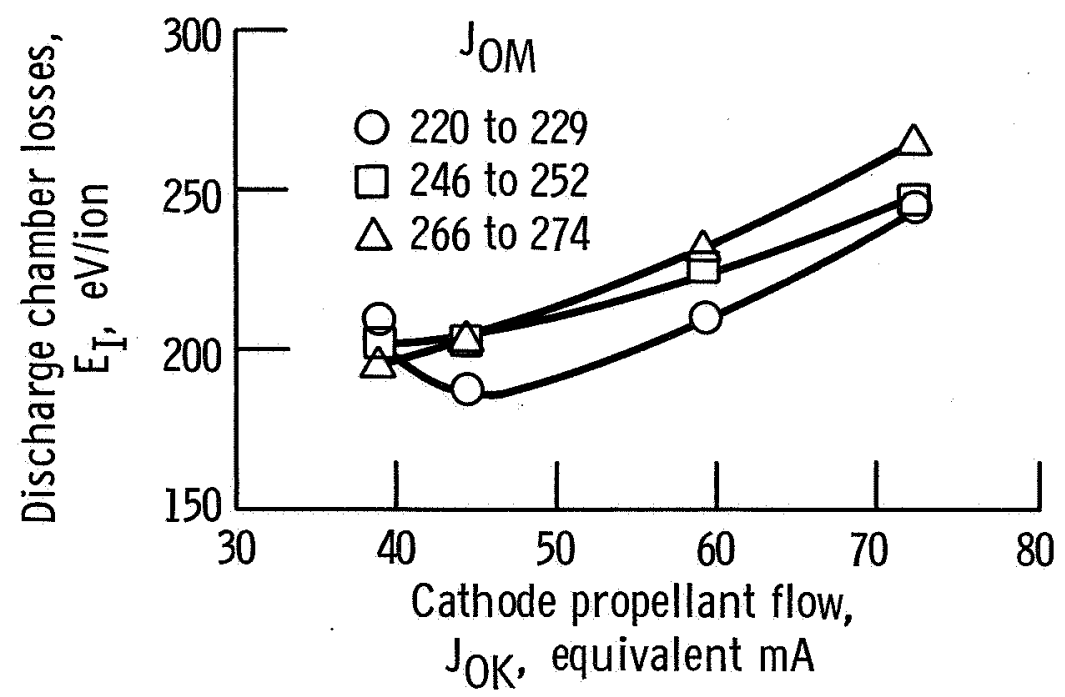

Figure 16. - Discharge chamber losses as a function of cathode propellant flow. Propellant utilization efficiency, $\eta_{\mathrm{U}}$, 85 percent.

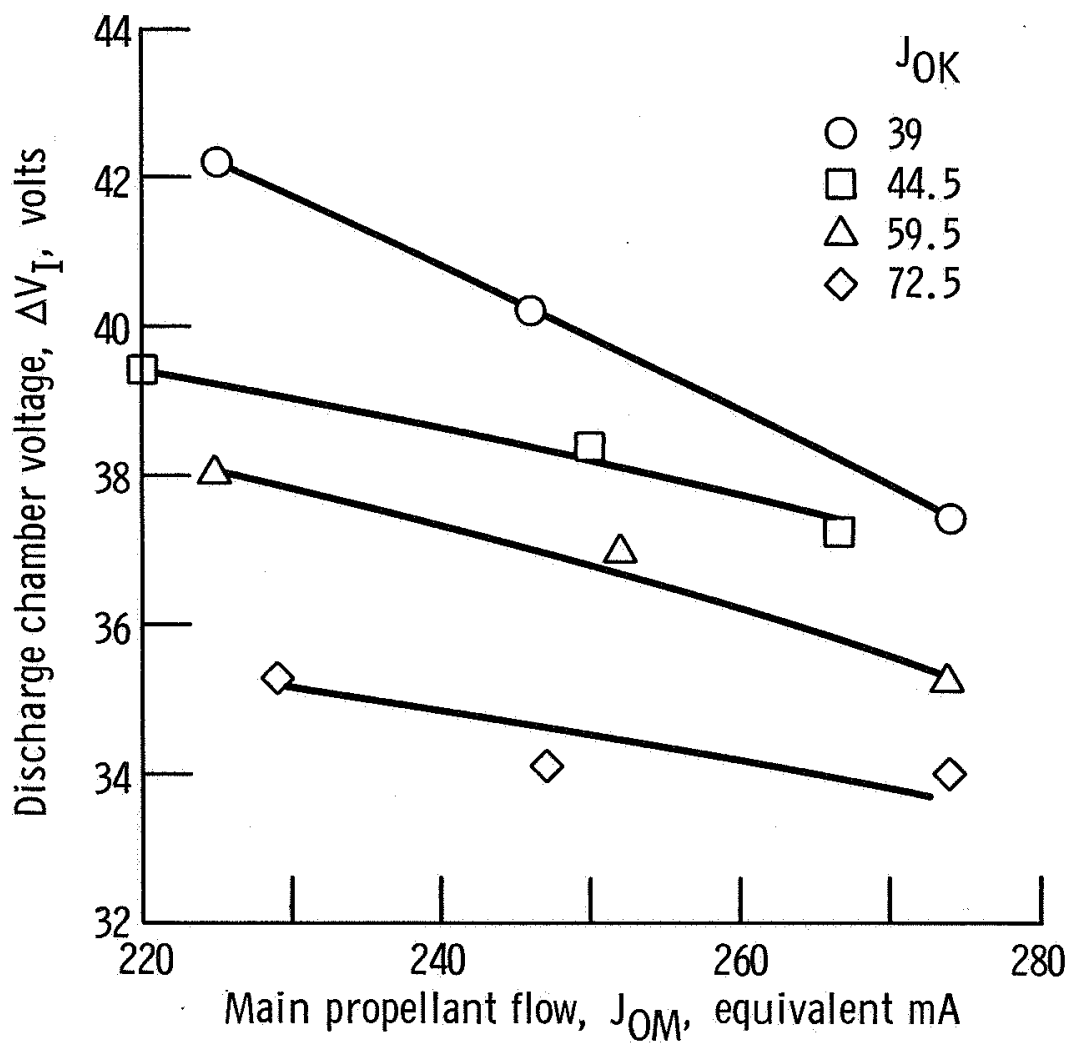

Figure 17. - Discharge chamber voltage as a function of main propellant flow. Propellant utilization efficiency, $\eta_{u}, 85$ percent. 


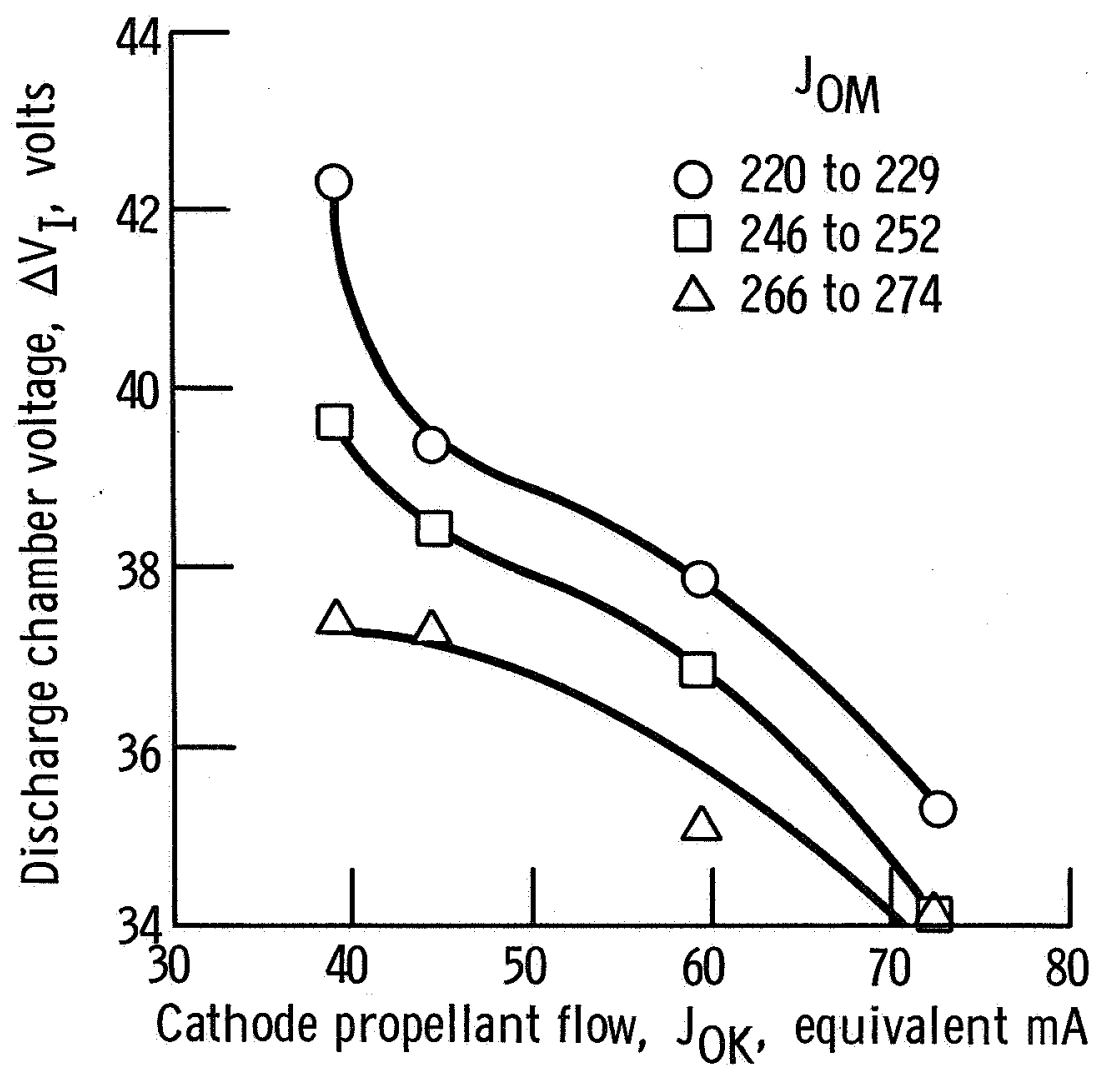

Figure 18. - Discharge chamber voltage as a function of cathode propellant flow. Propellant utilization efficiency, $\eta_{u}$, 85 percent.

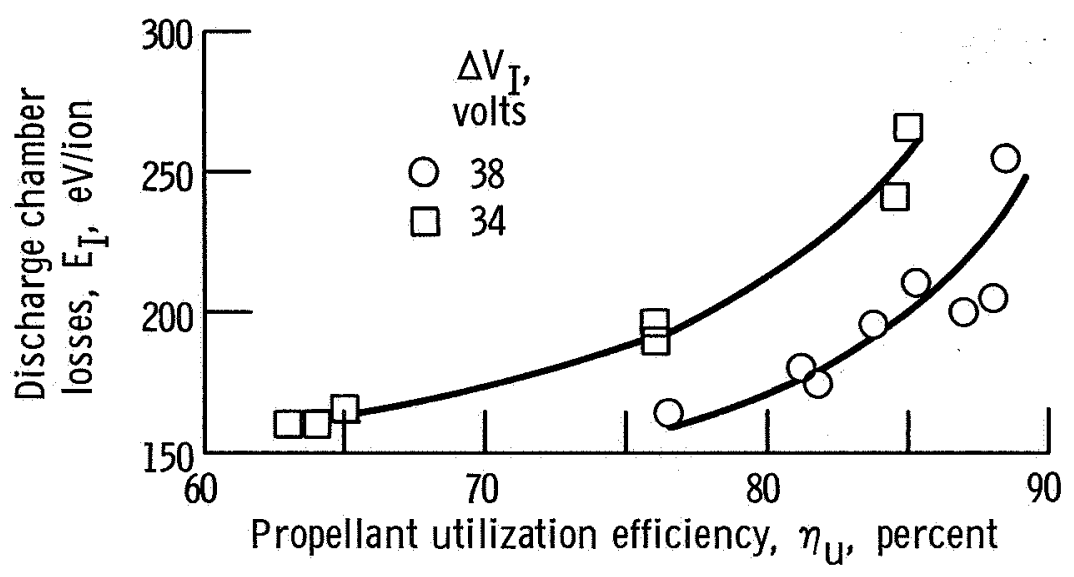

Figure 19. - Discharge chamber losses as a function of propellant utilization efficiency for constant discharge voltage. 